\title{
Estradiol matrix patches for pubertal induction: stability of cut pieces at different temperatures
}

\author{
Carina Ankarberg-Lindgren ${ }^{1}$, Aneta Gawlik ${ }^{2}$, Berit Kriström ${ }^{3}$, Laura Mazzanti ${ }^{4}$, Elisabeth J Ruijgrok ${ }^{5}$ and \\ Theo C J Sas ${ }^{6,7}$ \\ 'Department of Pediatrics, Institute of Clinical Sciences, The Sahlgrenska Academy, University of Gothenburg, Gothenburg, Sweden \\ 2Department of Pediatrics and Pediatric Endocrinology, Medical University of Silesia, School of Medicine, Katowice, Poland \\ ${ }^{3}$ Department of Clinical Sciences/Pediatrics, Umeå University, Umeå, Sweden \\ ${ }^{4}$ Pediatric Endocrinology and Rare Disease Unit, Department of Medical and Surgical Science, University of Bologna, Bologna, Italy \\ ${ }^{5}$ Department of Pharmacy, Erasmus Medical Center - Sophia Children's Hospital, University Medical Center Rotterdam, Rotterdam, the Netherlands \\ ${ }^{6}$ Department of Pediatric Endocrinology, Sophia Children's Hospital, University Medical Center Rotterdam, Rotterdam, the Netherlands \\ ${ }^{7}$ Diabeter, National Diabetes Care and Research Center, Rotterdam, the Netherlands
}

Correspondence should be addressed to C Ankarberg-Lindgren: carina.ankarberg-lindgren@gu.se

\begin{abstract}
Objective: Transdermal estradiol patches are primarily designed for adult women. No low-dose patches are licensed for pubertal induction in hypogonadal girls. Low doses can be achieved by cutting a matrix patch into smaller pieces. However, the manufacturers do not guarantee stability or utility of cut estradiol patches. The aim of the study was to assess 1-month stability of cut estradiol patches from four different manufacturers in the laboratory at room temperature $\left(+21^{\circ} \mathrm{C}\right)$ and at an elevated temperature $\left(+35^{\circ} \mathrm{C}\right)$. Design and methods: Estraderm MX $50 \mu \mathrm{g}$, Systen $50 \mu \mathrm{g}$ and Oesclim $25 \mu \mathrm{g}$ matrix patches were cut into eight pieces while Estradot $50 \mu \mathrm{g}$ small patches were cut in half. The cut patches were stored in their respective pouches at $+21^{\circ} \mathrm{C}$ or at $+35^{\circ} \mathrm{C}$ for up to 1 month. The estradiol drug was extracted from the patch by ethyl acetate $\mathrm{n}$-hexane and determined by radioimmunoassay.

Results: Storage at $+21^{\circ} \mathrm{C}$ or $+35^{\circ} \mathrm{C}$ up to 1 month did not reduce the estradiol concentration in Estraderm MX, Systen and Oesclim patches. However, although the estradiol in Estradot patches was not affected by storage at $+21{ }^{\circ} \mathrm{C}$, at $+35^{\circ} \mathrm{C}$, estradiol decreased by $57 \%( \pm 1 \%)$ in cut pieces.

Conclusions: Unused Estraderm MX, Systen and Oesclim patch pieces may be stored for at least 1 month at $\leq+35^{\circ} \mathrm{C}$. Where estradiol patches for children are not available, cut pieces of these or similar patches can be used for pubertal induction. The Estradot patch was too small to properly cut into low doses and not stable in elevated temperatures.
\end{abstract}

Key Words

- estrogen

- hormone replacement therapy

- patches

- pubertal induction

- stability
Endocrine Connections (2019) 8, 360-366

\section{Introduction}

Girls with hypogonadism require estrogen replacement therapy to induce puberty and maintain secondary sex characteristics, as well as to attain peak bone mass. These outcomes are achieved by starting with a low estradiol $\left(\mathrm{E}_{2}\right)$ dose, which is then gradually increased for about 3 years to an adult estrogen replacement therapy dose. Relatively high-dose estrogen replacement therapy at pubertal induction may result in rapid and unfavorable breast shape development and short stature as an adult, due to the accelerated skeletal maturation (1). Accordingly, stable and reliable low-dose estrogen replacement therapy products are essential for these girls.

The most common example of hypergonadotropic hypogonadism is Turner syndrome, resulting from gonadal dysgenesis. Most patients fail to enter puberty or show pubertal arrest. For the induction of puberty, oral

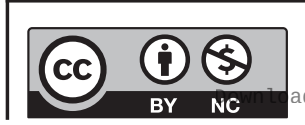


or transdermal $\mathrm{E}_{2}$ may be used. However, the available evidence suggests that transdermal administration could have a more favorable profile both in cost and efficacy than oral estrogen replacement therapy $(2,3)$. Transdermal estrogen replacement therapy has minimal, if any, effect on hepatic clotting factor production and other protein changes associated with the liver first-pass effect $(4,5)$. In individuals with Turner syndrome, estrogen replacement therapy will typically continue for at least 40 years, and therefore, should be administered in a route that most closely mimics hormone physiology. Consequently, the recently published international guideline for Turner syndrome recommend transdermal rather than oral $\mathrm{E}_{2}$ treatment where available $(6,7)$.

Transdermal $\mathrm{E}_{2}$ patches are primarily designed for postmenopausal women. The estimated dose required for pubertal induction is one-tenth to one-twentieth of the adult dose. Since no commercially available patches delivering such small doses, the physician, patient, parent or pharmacist has to manipulate formulations intended for adult women. This situation is further complicated by the need to adjust the dose to mimic the increasing $\mathrm{E}_{2}$ serum levels seen during the different stages of spontaneous puberty (8). These products are thus used not only off-label (i.e. not registered for this use) but also non-licensed, as the label does not provide data on the manipulated formulation.

Matrix patches consist of a monolayered adhesive matrix with uniformly distributed $\mathrm{E}_{2}$. For each formula of matrix patch, there is a linear relationship between the dose of $\mathrm{E}_{2}$ administered, which is determined by the surface area, and serum $\mathrm{E}_{2}$ concentrations. Consequently, cutting the $\mathrm{E}_{2}$ patches may be a way of providing lower doses. Unfortunately, manufacturers do not recommend cutting the $\mathrm{E}_{2}$ patches and claim they cannot guarantee uniform distribution of drug throughout the patch, despite the fact that this uniformity is a release criterion for pharmaceutical batches. This has raised questions from pharmacists and led to uncertainty among physicians, but the manufacturers have not shown any interest (motivation) in evaluating this problem.

Nevertheless, previous studies have shown that by cutting the $\mathrm{E}_{2}$ patch into smaller pieces, it is possible to provide an individualized dose for pubertal induction and thereby mimic hormone physiology $(3,9,10,11$, $12,13,14)$. However, members of the Turner Syndrome Working Group of the European Society of Paediatric Endocrinology (ESPE) consider it important to extend current knowledge on the use and storage of whole and cut patches for children, particularly to provide data that can be applied to different countries with different climates.

In this laboratory study, we evaluated four different brands of $\mathrm{E}_{2}$ matrix patches from different manufacturers to test their feasibility in pubertal induction by testing (a) the uniformity of drug $\mathrm{E}_{2}$ distribution on the surface area of the patches, (b) the stability of cut patches at room temperature $\left(+21^{\circ} \mathrm{C}\right)$ and (c) their stability in high temperatures $\left(+35^{\circ} \mathrm{C}\right)$, representing a hot climate.

\section{Materials and methods}

\section{Patches}

Four different brands of transdermal $\mathrm{E}_{2}$ patches of the matrix type available in Europe were chosen for testing: Systen (=Evorel) $50 \mu \mathrm{g}$ per $24 \mathrm{~h}$ (Janssen-Cilag International, Beerse, Belgium), Estraderm MX $50 \mu \mathrm{g}$ per $24 \mathrm{~h}$ (Merus Labs, Amsterdam, Netherlands), Oesclim (=Esclim, Esclima) $25 \mu \mathrm{g}$ per $24 \mathrm{~h}$ (Mylan Technologies, Canonsburg, PA, USA) and Estradot (=Vivelle dot) $50 \mu \mathrm{g}$ per $24 \mathrm{~h}$ (Novartis) (Fig. 1 and Table 1). All patches were guaranteed by the manufacturer to have an end-ofshelf-life content within acceptable margins of the labeldeclared concentration until expiry date if stored in the
A

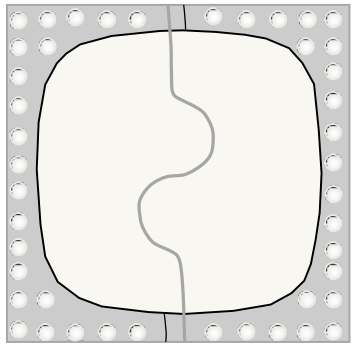

C

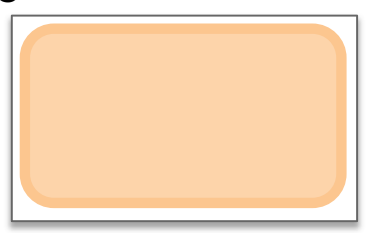

B

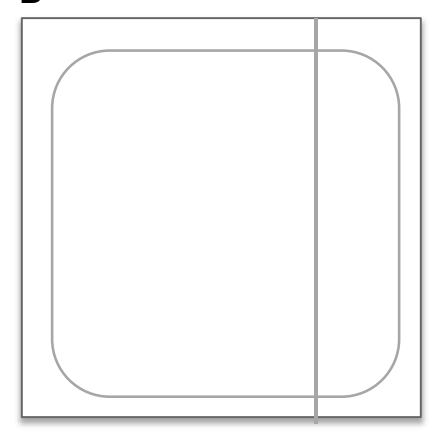

D

\section{Figure 1}

Sketched shapes of four different brands of estradiol matrix patches. (A) Systen (= Evorel) 50 g/24 h; (B) Estraderm MX $50 \mu \mathrm{g} / 24$ h; (C) Oesclim

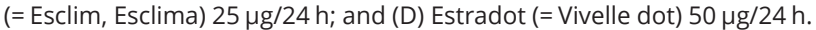
The estradiol patches are sketched in proportional size to each other. Gray lines across the patches in panels A, B and D show the incision for opening of the protective liner.

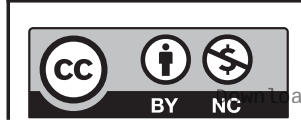

This work is licensed under a Creative Commons Attribution-NonCommercial 4.0 International License. ded from Bioscientifica.com at 04/26/2023 01:06:34PM 
Table 1 Description of four brands of $E_{2}$ matrix patch for potential use in pediatrics.

Manufacturer
Dose $(\mu \mathrm{g} / 24 \mathrm{~h})$
Amount of $\mathrm{E}_{2}(\mathrm{~m}$
Shape and color
Patch area $\left(\mathrm{cm}^{2}\right)$
Protective backin

Protective backing

Recommended storage conditions

\begin{tabular}{l} 
Systen (= Evorel) \\
\hline Janssen-Cilag International \\
50 \\
3.2 \\
Square with rounded \\
corners, transparent
\end{tabular}

16

A foiled release liner with an S-shaped center incision. Extending beyond the patch with dotted marks along the edge

In its protective pouch, below $+25^{\circ} \mathrm{C}$

\begin{tabular}{l}
\hline Estraderm $\mathbf{M X}$ \\
\hline Merus Labs \\
50 \\
1.5 \\
Square with rounded \\
corners, transparent
\end{tabular}

22

A polyester release liner with an incision. Extending beyond the patch

In its protective pouch, below $+25^{\circ} \mathrm{C}$

\begin{tabular}{l} 
Oesclim (= Esclim, Esclima) \\
\hline Mylan Technologies \\
25 \\
5 \\
Rectangular foam \\
mounting with rounded \\
corners, beige \\
11 \\
A polyester release liner \\
extending beyond the \\
patch, no incision
\end{tabular}

In its protective pouch, below $+25^{\circ} \mathrm{C}$
Estradot (= Vivelle dot)

Novartis

50

0.78

Rectangular with rounded corners, transparent

5

A polyester release liner with an incision. The same size as the patch

In its protective pouch, below $+30^{\circ} \mathrm{C}$. Do not store Estradot in refrigerator. Keep from freezing $201 \pm 54(20)$

$C_{\max } E_{2}(\mathrm{pmol} / \mathrm{L})$ with
$50 \mu \mathrm{p}$ per $24 \mathrm{~h}$ patch

$184 \pm 12(17)$

$143 \pm 92(18)$

$226 \pm 121(19)$

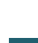

$C_{\max } E_{2}$, average peak plasma $E_{2}$ concentration determined in postmenopausal women with an average weight of $65 \mathrm{~kg}$; $E_{2}$, estradiol.

original protective pouch below $+25^{\circ} \mathrm{C}$ (Systen, Estraderm $\mathrm{MX}$, Oesclim) or below $+30^{\circ} \mathrm{C}$ (Estradot). In addition, Estradot was labeled 'Do not store Estradot in refrigerator. Keep from freezing'. Therefore, storage in the refrigerator was not an option. The patches were stored in the original protective pouch and carton at room temperature $\left(+21 \pm 1^{\circ} \mathrm{C}\right)$ until study start. The experiment was carried out between October 2017 and March 2018.

\section{Ensuring uniformity of drug distribution and optimal $\mathrm{E}_{2}$ extraction procedure}

In order to verify the uniform distribution of $\mathrm{E}_{2}$ on the surface area of the patches and to determine the optimal extraction procedure, a pre-study was performed. The patches, backed with a polyester or foiled release liner (Fig. 1 and Table 1), were taken out of the foil-lined pouches. After removal of the protective release liner, each patch was attached to a filter paper (Whatman 903 for newborn screening; PerkinElmer). Thereafter, patches were cut with scissors into between two to eight equal pieces, depending on the size and shape of the patch (Fig. 2). For Estradot, four patches were used in order to obtain eight pieces. Measurement before cutting was performed with a ruler. $\mathrm{E}_{2}$ drug concentrations were determined in all cut pieces directly without storage.

\section{Stability testing of $E_{2}$ drug amount in cut patches}

Patches of each variety were taken out of the foil-lined pouches. Systen, Estraderm MX and Oesclim patches were

$\begin{array}{lr}\text { https://ec.bioscientifica.com } & \text { (c) } 2019 \text { The authors } \\ \text { https://doi.org/10.1530/EC-19-0025 } & \text { Published by Bioscientifica Ltd }\end{array}$

cut with scissors into eight pieces (Fig. 2, panel A, B and C), while the small Estradot patches were cut into two pieces (Fig. 2D). Patch pieces protected with their polyester or foiled release liner were put back into their protective pouches and sealed by hand. Half of the pouches were put in airtight plastic bags, air pressed and sealed with a zipper (PerkinElmer). The patches were stored for up to 1 month, either in a drawer
A

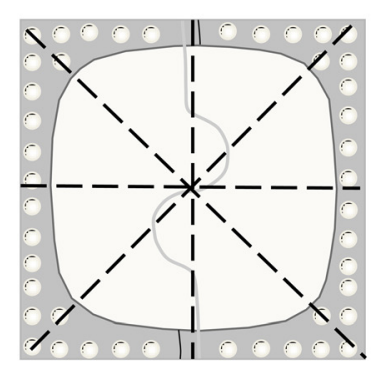

C

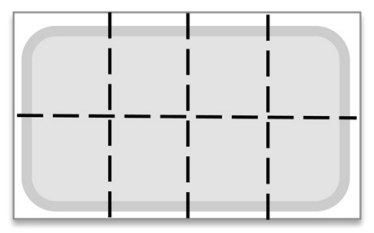

B

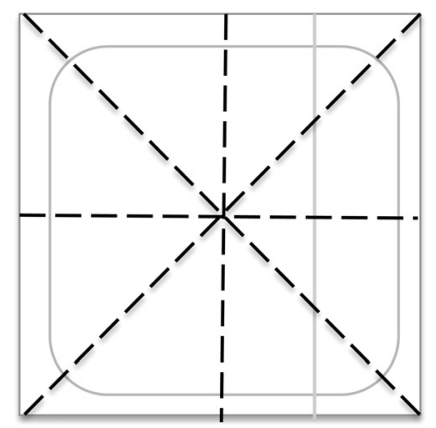

$\mathrm{D}$

\section{Figure 2}

Cutting of estradiol matrix patches. (A) Systen $50 \mu \mathrm{g} / 24 \mathrm{~h}$, (B) Estraderm MX $50 \mu g / 24 h$ and (C) Oesclim $25 \mu \mathrm{g} / 24 \mathrm{~h}$ were cut into eight pieces, while (D) Estradot $50 \mu \mathrm{g} / 24 \mathrm{~h}$ was cut in half. The dashed lines depict how the patches were cut in the present study. 
at room temperature, $+21^{\circ} \mathrm{C}\left( \pm 1^{\circ} \mathrm{C}\right)$ or in a heating cabinet at $+35^{\circ} \mathrm{C}\left( \pm 1^{\circ} \mathrm{C}\right)$ to represent storage conditions in a hot climate. Intact patches in unopened pouches were sealed in the same manner (half in airtight plastic bags) and stored under the same conditions for comparison and analyzed in parallel. During the first 14 days, two pieces of each patch variety stored at room temperature were analyzed every third to fourth day and thereafter once a week. Estradot patches were analyzed once a week. Patch pieces stored at $+35^{\circ} \mathrm{C}$ were analyzed after 2 and 4 weeks. The entire experiment was performed in duplicate.

\section{Extraction of $E_{2}$ drug from patch pieces}

Each piece of the $E_{2}$ patches was removed from the protective liner and attached to a matched-size filter paper (Whatman 903 for newborn screening; PerkinElmer). The patch pieces on filter paper were thereafter put in glass tubes with a solution of $3.5 \mathrm{~mL}$ ethyl acetate/n-hexane $(2: 3$ by volume; VWR International AB, Stockholm, Sweden). The $\mathrm{E}_{2}$ was extracted from the patch into the solvent by gentle vortex for $30 \mathrm{~min}$. The samples were thereafter serially diluted (1:176 and 1:76) with ethyl acetate/n-hexane to a final volume of $1.5 \mathrm{~mL}$. The organic phase was dried on a $37^{\circ} \mathrm{C}$ heat block under a stream of nitrogen and suspended in free steroids matrix (MSG3000; Golden West Diagnostics, Temecula, CA, USA). After a final dilution 1:16, samples were ready for $\mathrm{E}_{2}$ quantification by radioimmunoassay (RIA).

\section{$\mathrm{E}_{2}$ determination}

Drug $\mathrm{E}_{2}$ concentrations were determined in duplicate by an in-house RIA at the Department of Pediatrics, Göteborg Pediatric Growth Research Center in Gothenburg, Sweden. Certified reference material was purchased from Sigma-Aldrich. A stock calibrator was prepared in absolute ethanol and thereafter diluted with MSG3000 blank serum to make six calibrators in the range $0-5000 \mathrm{pmol} / \mathrm{L}$. Tracer and $\mathrm{E}_{2}$ antibody-coated tubes (ESTR-US-CT) were purchased from Cisbio Bioassays (Codolet, France). All other reagents were purchased from VWR International $\mathrm{AB}$ and were of the highest purity available. The lower limit of detection was $9 \mathrm{pmol} / \mathrm{L}$. The total coefficient of variation (CV) was $9 \%$ for $250 \mathrm{pmol} / \mathrm{L}$ and above. The assay procedure has been described previously and validated accordingly $(15,16)$.

\section{Statistical analyses}

Results are presented as median \pm range unless stated otherwise. The $\mathrm{E}_{2}$ concentration in cut patches (stored at $+21^{\circ} \mathrm{C}$ and $+35^{\circ} \mathrm{C}$ in their original pouches versus in an airtight plastic bag) are presented as a percentage of the $\mathrm{E}_{2}$ content in the original product (intact sealed patches stored at $\left.+21^{\circ} \mathrm{C}\right)$. A deviation of $\pm 20 \%$ from the original product was considered an acceptable variance.

\section{Results}

\section{Validity of the drug extraction procedure and uniformity on the patches}

The $\mathrm{E}_{2}$ drug amount was adequately extracted from all four patches that were tested: $128 \pm 7 \%$ recovery for Systen, $106 \pm 14 \%$ for Estraderm MX, 126 $\pm 6 \%$ for Oesclim and $115 \pm 5 \%$ for Estradot. The extraction also yielded a uniform distribution of $\mathrm{E}_{2}$ drug concentrations on Systen (CV between the eight cut pieces was 9\%), Estraderm MX (CV 10\%), Oesclim (CV 11\%) and Estradot (CV 13\%) patch surface areas. This combined result confirmed the validity of the study design.

\section{Stability of $E_{2}$ drug in cut patches at $+21^{\circ} \mathrm{C}$}

Storage at room temperature for up to 1 month did not affect the $\mathrm{E}_{2}$ concentration in any of the tested patches. All data fell within analytical variability of $4.1 \pm 6.4 \%$ deviation for Systen, $9.1 \pm 1.3 \%$ for Estraderm MX, $3.3 \pm 2.2 \%$ for Oesclim and $6.6 \pm 10.0 \%$ for Estradot after 1 month of storage at $+21^{\circ} \mathrm{C}$, compared to an intact patch in an unopened pouch (Fig. 3). Storage in a plastic bag yielded similar results (Fig. 3).

\section{Stability of $E_{2}$ drug in cut patches in the high- temperature storage condition}

Storage at $+35^{\circ} \mathrm{C}$ for up to 1 month did not affect the $\mathrm{E}_{2}$ concentration on intact and sealed Systen, Estraderm MX and Oesclim patches (Fig. 3, panel A, B and C). In addition, the concentration of $\mathrm{E}_{2}$ was stable in cut patches with $-6.9 \pm 6 \%$ deviation for Systen, $-15.8 \pm 1.5 \%$ for Estraderm MX and $-5.0 \pm 3.8 \%$ for Oesclim after 1 month of storage at $+35^{\circ} \mathrm{C}$, compared to an intact patch in an unopened pouch stored at $+21^{\circ} \mathrm{C}$ (Fig. 3, panel A, B and C). No difference in $\mathrm{E}_{2}$ concentration was observed between storage in a plastic bag or in the pouch only.

However, the $\mathrm{E}_{2}$ drug concentration in the Estradot patch deteriorated with storage at $+35^{\circ} \mathrm{C}$. The $\mathrm{E}_{2}$ decreased by $33 \%( \pm 11 \%)$ in intact sealed patches and by $57 \%( \pm 1 \%)$ in cut pieces during 1 month of storage (Fig. 3D). Storage in airtight plastic bags gave similar results as storage in the pouch only.

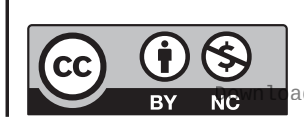

This work is licensed under a Creative Commons Attribution-NonCommercial 4.0 International License. ded from Bioscientifica.com at 04/26/2023 01:06:34PM 
A

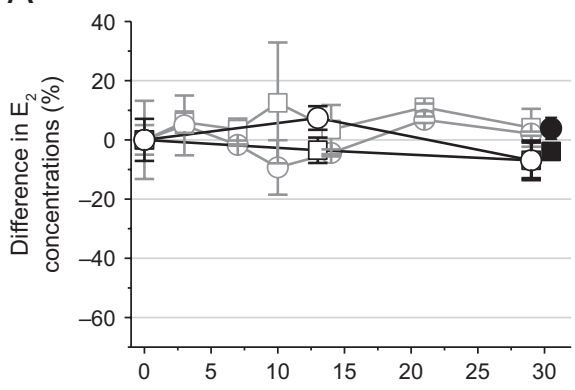

C

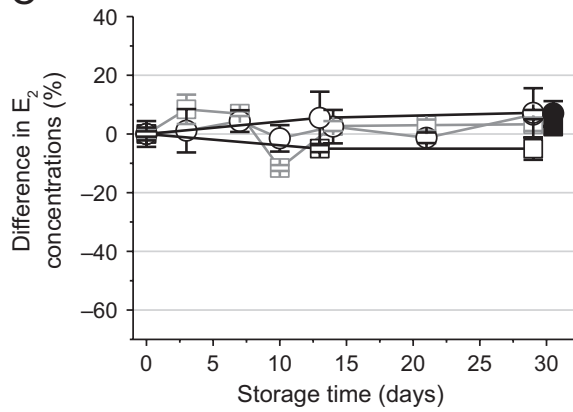

B

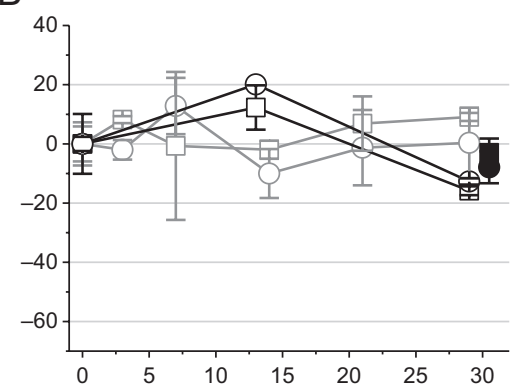

D

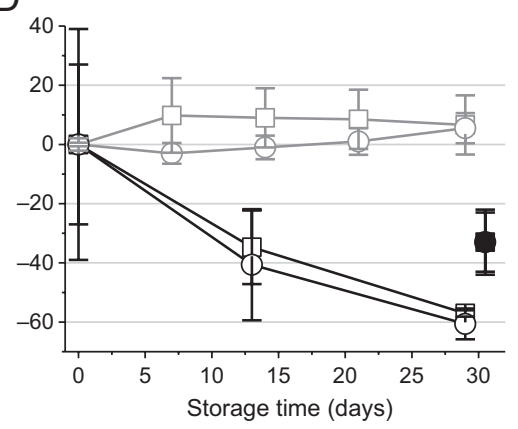

Figure 3

Evaluation of stability of four different $E_{2}$ matrix patches. (A) Systen (= Evorel); (B) Estraderm MX; (C) Oesclim (= Esclim, Esclima); and (D) Estradot (= Vivelle dot). Patches were cut into pieces and stored either at $+21 \pm 1^{\circ} \mathrm{C}$ (gray lines) or at $+35 \pm 1{ }^{\circ} \mathrm{C}$ (black lines) for up to 1 month. Half of the tested patches were stored in the original pouch (square symbols) and the other half in the pouch inside a small sealed airtight plastic bag (circle symbols). Filled symbols depict patches stored intact and sealed for 30 days at $+35^{\circ} \mathrm{C}$. Results are presented as median difference in $\mathrm{E}_{2}$ drug concentrations \pm range compared to an intact patch that had been stored sealed in its original pouch at $+21^{\circ} \mathrm{C}$ until cut and analyzed in parallel. $\mathrm{E}_{2}$, estradiol.

\section{Practical experience with using the patches in this experiment}

Three of the patches, Systen, Estraderm MX and Oesclim, were large and easy to cut. They were covered with a protective liner that was larger than the patch itself by a generous margin (Fig. 1 and Table 1), which was an advantage for easy removal and application. Oesclim was a thicker patch compared to the others, rectangular in shape and very easy to cut and handle. Square-shaped patches with rounded corners were easier to cut into equal wedges than into perfect rectangles (Fig. 2). For the purposes of this study, we cut the patches to a practical size that would ensure accuracy. These patches adhered well on the filter paper after cutting and storage.

The Estradot patch was a miniature rectangular patch, which was too small to be properly cut into small pieces. Smaller pieces than $1 / 8$ of a $50 \mu \mathrm{g}$ patch $\left(0.6 \mathrm{~cm}^{2}\right)$ were extremely difficult to handle. The protective liner had no extra space surrounding the patch itself (Fig. 1), and it was therefore difficult to remove the protective liner from the patch when cut into small pieces. Only the pieces surrounding the incision could easily be separated from the protective liner. The substance of the content on the Estradot patch surface was thicker and more glutinous compared to the other brands. When the Estradot patch was cut with scissors, a small amount of this content leaked out. However, the patch adhered well on the filter paper after cutting and storage. In the extraction procedure, the drug contents turned gray in the solvent phase, which did not occur with the other three products.

\section{Discussion}

This is the first report on the utility and stability of $\mathrm{E}_{2}$ matrix patches in cut pieces as well as the impact of storage in higher temperatures. This study showed that the $\mathrm{E}_{2}$ drug amount was uniformly distributed over the tested $\mathrm{E}_{2}$ matrix patches Systen, Estraderm MX and Oesclim, and we therefore consider it safe to cut these patches into smaller pieces. In addition, we have demonstrated that the cut patches can be safely stored in their original protective pouches for up to 1 month at $+35^{\circ} \mathrm{C}$. The Estradot patch is very small and can be safely cut in half; however, it did not meet our stability criteria.

Pediatricians will, in general, prefer to use registered and licensed products. Nevertheless, in the absence of very-low-dose $E_{2}$ patches, cutting patches of one of the three studied brands Systen, Estraderm MX and Oesclim will reliably deliver the correct dose when used directly after cutting into pieces or after storage of up to 1 month. This study indicates that $\mathrm{E}_{2}$ matrix patches with similar size and shape will behave in the same manner. Consequently, we expect that more pediatricians in different countries with different climates will be encouraged to choose transdermal $\mathrm{E}_{2}$ treatment
This work is licensed under a Creative Commons Attribution-NonCommercial 4.0 International License. ded from Bioscientifica.com at 04/26/2023 01:06:34PM via free access 
according to the guidelines for girls with hypogonadism $(6,7)$. Traveling with patches will not be an issue as those patches were found to be relatively resistant to higher temperatures. However, controlled trials are still needed in order to determine which regimen provides the best clinical outcomes. This study brings us one step closer to future clinical studies involving cut pieces of transdermal $\mathrm{E}_{2}$ matrix patches.

Three of the patches, Systen, Estraderm MX and Oesclim, were relatively large and covered with a generously sized protective liner which made them easy to cut. In this study, the patches were cut into eight pieces for practical reasons. Nonetheless, cutting into sixteen pieces is possible and has been used in clinical practice (12); this would not have changed the results in this experimental study. In daily practice, precise cutting is not crucial as long as a larger patch is cut with $\pm 1 \mathrm{~mm}$ error, but, particularly for the convenience and safety of the youngest patients using a very low dose, it would be preferable if the pharmacist cut the patch to ensure precision.

The least stable patch was the Estradot patch. This miniature $\mathrm{E}_{2}$ patch is cosmetically preferable for adult women, but it was too small to properly cut into small pieces. Like the Systen and Estraderm MX patch, it was designed to deliver $50 \mu$ g per $24 \mathrm{~h}$, but with a lower drug $\mathrm{E}_{2}$ concentration $(0.78 \mathrm{mg})$, on a surface area that was just one-quarter to one-third of the surface area of those two brands. We assume that in order to obtain the same delivery criteria on a small area, the content on the Estradot patch surface was thicker compared to the others. In practice, the Estradot patch may be cut into $6 \mu \mathrm{g}\left(0.6 \mathrm{~cm}^{2}\right)$ pieces, that is $1 / 8$ of a $50 \mu \mathrm{g}$ patch or $1 / 4$ of a $25 \mu \mathrm{g}$ patch. Smaller pieces were impractical to handle, and cutting such small patches would be prone to inaccuracies. Only the pieces surrounding the incision could easily be removed from the release liner, which leads us to suspect that users in many cases have to discard the unusable patch fractions. Nonetheless, it seems that some users manage to cut even smaller pieces (11).

We favor physiologically administered estrogen replacement therapy, in other words, mimicking the diurnal variation of $E_{2}$ seen in early puberty by nocturnal application of a cut piece (approximately $3 \mu \mathrm{g}$ ) of an $\mathrm{E}_{2}$ patch $(9,12)$. For this reason, the Estradot patch is not applicable for pubertal induction in the youngest girls with the lowest weight. We recommend using the Estradot $\mathrm{E}_{2}$ patch only in older girls who weigh more, since the proposed regimen of starting with a $6 \mu \mathrm{g}$ patch piece and applying it for 3-4 days per week (3) has not been evaluated clinically. Another consideration is that the Estradot $\mathrm{E}_{2}$ patch is unstable both in the fridge (according to the manufacturer's information) and in hot temperatures (in our experiment), which limits its utility in some climates.

The patches tested in this study were comparable in terms of $\mathrm{E}_{2}$ delivery into the blood, indicating no difference in serum or plasma $\mathrm{E}_{2}$ concentrations (about $200 \mathrm{pmol} / \mathrm{L})$ with $50 \mu \mathrm{g} \mathrm{E}_{2}$ patches in postmenopausal women $(17,18,19,20)$. The inter-individual variation has been reported to be less with transdermal $\mathrm{E}_{2}$ patches (three-fold) compared to transdermal gel (seven-fold) (21). Although only four brands of $E_{2}$ matrix patches were tested in this study, we assume that the results are applicable to other similar $\mathrm{E}_{2}$ matrix patches.

One limitation of this study is that the effect of humidity was not tested. Although the absence of guidance from the manufacturer suggests that humidity is not an issue for storage, we do not rule out the possibility of an effect. On the other hand, $E_{2}$ is only slightly soluble in water, and we therefore believe that humidity will have little impact on stability. Until this is established, we recommend using an airtight plastic bag in order to avoid any effect of humidity during storage. This study yielded no difference in stability with or without a plastic bag. All cut patches adhered well on the filter paper after storage for up to 1 month. Although we did not test the cut patches on skin, we assume that the adhesive quality would not differ.

\section{Conclusions}

The drug amount was uniformly distributed over the surface area of the tested Estraderm MX, Oesclim, Systen and Estradot $\mathrm{E}_{2}$ matrix patches, and we therefore consider it safe to cut the patches into smaller pieces. The Estraderm MX, Oesclim and Systen $E_{2}$ patches are large enough to easily be cut into small pieces, in order to achieve very low $\mathrm{E}_{2}$ doses. Unused patch pieces were stable for at least 1 month in the original protective pouch at up to $+35^{\circ} \mathrm{C}$. Since $E_{2}$ patches for children are not available, cut pieces of these three brands of $E_{2}$ matrix patch can be used to induce puberty in hypogonadal girls. The Estradot $\mathrm{E}_{2}$ patch, however, was too tiny to properly cut into small pieces for pubertal induction and not stable for storage in a hot climate.

\section{Declaration of interest}

The authors declare that there is no conflict of interest that could be perceived as prejudicing the impartiality of the research reported.

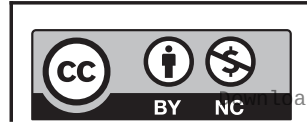

This work is licensed under a Creative Commons Attribution-NonCommercial 4.0 International License. ded from Bioscientifica.com at 04/26/2023 01:06:34PM 


\section{Funding}

This work was supported by Pfizer (grant numbers WP1345320). No Pfizer products were involved in this study.

\section{References}

1 Cutler Jr GB. The role of estrogen in bone growth and maturation during childhood and adolescence. Journal of Steroid Biochemistry and Molecular Biology 199761 141-144. (https://doi.org/10.1016/S09600760(97)80005-2)

2 Shah S, Forghani N, Durham E \& Neely EK. A randomized trial of transdermal and oral estrogen therapy in adolescent girls with hypogonadism. International Journal of Pediatric Endocrinology 2014 2014 12. (https://doi.org/10.1186/1687-9856-2014-12)

3 Matthews D, Bath L, Hogler W, Mason A, Smyth A \& Skae M. Hormone supplementation for pubertal induction in girls. Archives of Disease in Childhood 2017102 975-980. (https://doi.org/10.1136/ archdischild-2016-311372)

4 Scarabin PY, Oger E, Plu-Bureau G \& EStrogen and THromboEmbolism Risk Study Group. Differential association of oral and transdermal oestrogen-replacement therapy with venous thromboembolism risk. Lancet 2003362 428-432. (https://doi. org/10.1016/S0140-6736(03)14066-4)

5 Canonico M, Oger E, Plu-Bureau G, Conard J, Meyer G, Levesque H, Trillot N, Barrellier MT, Wahl D, Emmerich J, et al. Hormone therapy and venous thromboembolism among postmenopausal women: impact of the route of estrogen administration and progestogens: the ESTHER study. Circulation 2007115 840-845. (https://doi. org/10.1161/CIRCULATIONAHA.106.642280)

6 Klein KO, Rosenfield RL, Santen RJ, Gawlik AM, Backeljauw PF, Gravholt CH, Sas TCJ \& Mauras N. Estrogen replacement in Turner syndrome: literature review and practical considerations. Journal of Clinical Endocrinology and Metabolism 2018103 1790-1803. (https:// doi.org/10.1210/jc.2017-02183)

7 Gravholt $\mathrm{CH}$, Andersen NH, Conway GS, Dekkers OM, Geffner ME, Klein KO, Lin AE, Mauras N, Quigley CA, Rubin K, et al. Clinical practice guidelines for the care of girls and women with Turner syndrome: proceedings from the 2016 Cincinnati International Turner Syndrome Meeting. European Journal of Endocrinology 2017 177 G1-G70. (https://doi.org/10.1530/EJE-17-0430)

8 Ankarberg-Lindgren C \& Norjavaara E. Estradiol in pediatric endocrinology. American Journal of Clinical Pathology 2009132 978-980. (https://doi.org/10.1309/AJCPA65OUUFASOAN)

9 Ankarberg-Lindgren C, Elfving M, Wikland KA \& Norjavaara E. Nocturnal application of transdermal estradiol patches produces levels of estradiol that mimic those seen at the onset of spontaneous puberty in girls. Journal of Clinical Endocrinology and Metabolism 2001 86 3039-3044. (https://doi.org/10.1210/jcem.86.7.7667)

10 Soriano-Guillen L, Coste J, Ecosse E, Leger J, Tauber M, Cabrol S, Nicolino M, Brauner R, Chaussain JL \& Carel JC. Adult height and pubertal growth in Turner syndrome after treatment with recombinant growth hormone. Journal of Clinical Endocrinology and Metabolism 200590 5197-5204. (https://doi.org/10.1210/ jc.2005-0470)

11 Davenport ML. Approach to the patient with Turner syndrome. Journal of Clinical Endocrinology and Metabolism 201095 1487-1495. (https://doi.org/10.1210/jc.2009-0926)

12 Ankarberg-Lindgren C, Kristrom B \& Norjavaara E. Physiological estrogen replacement therapy for puberty induction in girls: a clinical observational study. Hormone Research in Paediatrics 201481 239-244. (https://doi.org/10.1159/000356922)

13 Cakir ED, Saglam H, Eren E, Ozgur T \& Tarim ÖF. Retrospective evaluation of pubertal development and linear growth of girls with Turner syndrome treated with oral and transdermal estrogen. Journal of Pediatric Endocrinology and Metabolism 201528 1219-1226. (https://doi.org/10.1515/jpem-2014-0007)

14 Gawlik AM, Hankus M, Szeliga K, Antosz A, Gawlik T, Soltysik K, Drosdzol-Cop A, Wilk K, Kudela G, Koszutski T, et al. Late-onset puberty induction by transdermal estrogen in Turner syndrome girls - a longitudinal study. Frontiers in Endocrinology 2018923 . (https:// doi.org/10.3389/fendo.2018.00023)

15 Ankarberg-Lindgren C \& Norjavaara E. A purification step prior to commercial sensitive immunoassay is necessary to achieve clinical usefulness when quantifying serum 17beta-estradiol in prepubertal children. European Journal of Endocrinology 2008158 117-124. (https://doi.org/10.1530/EJE-07-0403)

16 Ankarberg-Lindgren C, Dahlgren J \& Andersson MX. Highsensitivity quantification of serum androstenedione, testosterone, dihydrotestosterone, estrone and estradiol by gas chromatographytandem mass spectrometry with sex- and puberty-specific reference intervals. Journal of Steroid Biochemistry and Molecular Biology 2018 183 116-124. (https://doi.org/10.1016/j.jsbmb.2018.06.005)

17 Reginster JY, Albert A, Deroisy R, Colette J, Vrijens B, Blacker C, Brion N, Caulin F, Mayolle C, Regnard A, et al. Plasma estradiol concentrations and pharmacokinetics following transdermal application of Menorest 50 or Systen (Evorel) 50. Maturitas 199727 179-186. (https://doi.org/10.1016/S0378-5122(97)00027-3)

18 Rohr UD, Nauert C \& Stehle B. 17beta-estradiol delivered by three different matrix patches $50 \mu \mathrm{g} /$ day: a three way cross-over study in 21 postmenopausal women. Maturitas 199933 45-58. (https://doi. org/10.1016/S0378-5122(99)00039-0)

19 Guichard JP, Sauron R \& Jones AB. Comparison of the pharmacokinetics of 17 beta-estradiol after a single 4-day application of Oesclim 50, Oesclim 100, and Vivelle 0.05 (Menorest 50) transdermal delivery systems. Journal of Clinical Pharmacology 1999 39 811-816. (https://doi.org/10.1177/00912709922008470)

20 Hossain M, Quebe-Fehling E, Sergejew T, Schmidt G, Skerjanec A, Cohen A, Krinsky L \& Ibarra de Palacios P. Comparative bioequivalence studies with Estradot and Menorest transdermal systems. Maturitas 200346 187-198. (https://doi.org/10.1016/S03785122(03)00190-7)

21 Jarvinen A, Nykanen S \& Paasiniemi L. Absorption and bioavailability of oestradiol from a gel, a patch and a tablet. Maturitas 199932 103-113. (https://doi.org/10.1016/S0378-5122(99)00021-3)

Received in final form 27 February 2019

Accepted 8 March 2019

Accepted Preprint published online 8 March 2019 https://ec.bioscientifica.com https://doi.org/10.1530/EC-19-0025 (c) 2019 The authors Published by Bioscientifica Ltd

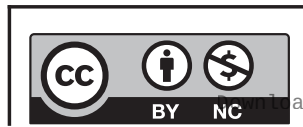

This work is licensed under a Creative Commons Attribution-NonCommercial 4.0 International License. ded from Bioscientifica.com at 04/26/2023 01:06:34PM 